\title{
Future Trends in Transport Infrastructure Monitoring
}

\author{
Simona Fontul
}

Simona Fontul

National Laboratory for Civil Engineering, Portugal

Corresponding author: Simona Fontul, simona@lnec.pt

https://doi.org/10.5592/C0/FTCE.2019.12

Scientific Symposium FUTURE TRENDS IN CIVIL ENGINEERING

Zagreb, Croatia, 17 October 2019 


\section{Future Trends in Transport Infrastructure Monitoring}

\section{Abstract}

The intense traffic on existing pavements not only induces increased deterioration but also decreases availability of pavements for monitoring and maintenance interventions. In Europe, in general, the existing pavement network requires maintenance in order to comply with traffic requirements. In an economic scenario of financial requirements, it is crucial to plan and justify maintenance measures needed for an efficient management. This paper presents future trends in pavement engineering focussing specifically on the non-destructive continuous monitoring, data processing, and possible applications of Building Information Modelling, as improved tools for pavement monitoring and rehabilitation management.

Key words: pavement condition, FWD, GPR, BIM, structural evaluation, monitoring

\section{Novi trendovi u praćenju stanja prometne infrastrukture}

\section{Sažetak}

Veliko prometno opterećenje ne samo da uzrokuje ubrzanu degradaciju postojećih kolnika već i značajno otežava postupak sustavnog praćenja njihova stanja i održavanja. Općenito, postojeće cestovne mreže u Europi potrebno je redovito održavati kako bi mogle preuzeti zahtijevano prometno opterećenje. S ekonomskoga gledišta, ključni parametri za učinkovito upravljanje kolnicima su planiranje i dokaz o opravdanosti odabranih mjera održavanja. $U$ radu su opisani novi trendovi u postupku gospodarenja kolnicima, s naglaskom na primjenu nerazornih kontinuiranih metoda praćenja, obradu podataka te mogućnost primjene informacijskog modela građevine (BIM-a) kao pomoćnog alata u postupku praćenja stanja i sanacije kolnika.

Ključne riječi: stanje kolnika, FWD, GPR, BIM, strukturna analiza, praćenje 


\section{Introduction}

The intense traffic on existing pavements induces increased deterioration. Maintenance measures are frequently required earlier than the end of the designed life span of the pavement. In order to have an efficient management, technically and financially, it is important to gather pavement condition information throughout the pavement life cycle and to forecast its deterioration over time. Specific maintenance measures, aiming to mitigate the causes of deterioration, can prolong the pavement residual life and guarantee its performance at an adequate level.

Non-destructive continuous monitoring of pavements, conducted on a systematic basis, is an essential tool for pavement management. Nevertheless, in spite of gathering many data, the processing is still time consuming and is generally used at the project level, for rehabilitation, rather than for preventive and planning purposes.

Building Information Modelling (BIM) is a methodology that is suitable for the entire AECO industry (Architecture, Engineering, Construction and Operation) as it allows representation of structural and functional characteristics of a construction, including activities, among other information. The main feature of BIM is the three-dimensional modelling system that includes the management, sharing and exchanging data across the entire life cycle of a structure, where each element or object has information of its physical data. The BIM methodology allows for better coordination and collaboration between the participants on the project, enabling simultaneous and real-time access, quick detection of conflicts between components and, consequently, a cost reduction. When it comes to evaluation of the road and airport infrastructure, and its bearing capacity and life cycle, it is important to identify contribution of non-destructive tests to the quality control during the construction of such infrastructure facilities, including railways, and to carry out load tests during their service life.

Non-destructive load tests allow establishment of structural behaviour models. In this sense, it would be appropriate to develop a more expeditious methodology based on in situ tests in order to optimize structural analysis of pavements, so as to identify in an expedite way the quality of the pavement and eventually, the locations that require reinforcement.

Some future approaches that can be applied to transport infrastructure monitoring and evaluation are presented in this paper, with the focus on the measurement procedure and the data processing involving the use of the Ground Penetrating Radar. Examples of possible application of BIM methodology to pavement monitoring and rehabilitation are given. Finally, the remote sensing as a tool for risk assessment in pavements management is also considered. 


\section{Advanced Ground Penetrating Radar (GPR) application}

\subsection{Traditional application}

The GPR is a non destructive test that is used in pavement evaluation mainly to assess layer thicknesses and to detect changes in structure [I],[2],[3].

Normally, pavements defects are detected during a visual inspection campaign and appropriate maintenance measures are adopted. These measures solve the effect of the problem but do not address the cause. The use of GPR, together with other tests, such us load tests, enable identification of the cause of degradation [2],[3],[4]. GPR is particularly efficient in detecting subsurface changes in the structure, even when they are hardly visible at the surface. Figure I presents an example of a test in which GPR was used to identify the presence of a weak subgrade that caused settlements. The pavement was then systematically repaired by adding bituminous mixtures. The test pit confirmed that the bituminous layer thickness was more than double when compared to the remaining sections, namely $40 \mathrm{~cm}$ instead of $20 \mathrm{~cm}$. The systematic repairing was only increasing the settlement by overloading a weak subgrade.

This shows the importance of GPR in detecting the causes and enabling proper intervention, treating the subgrade, as was done in this particular case.

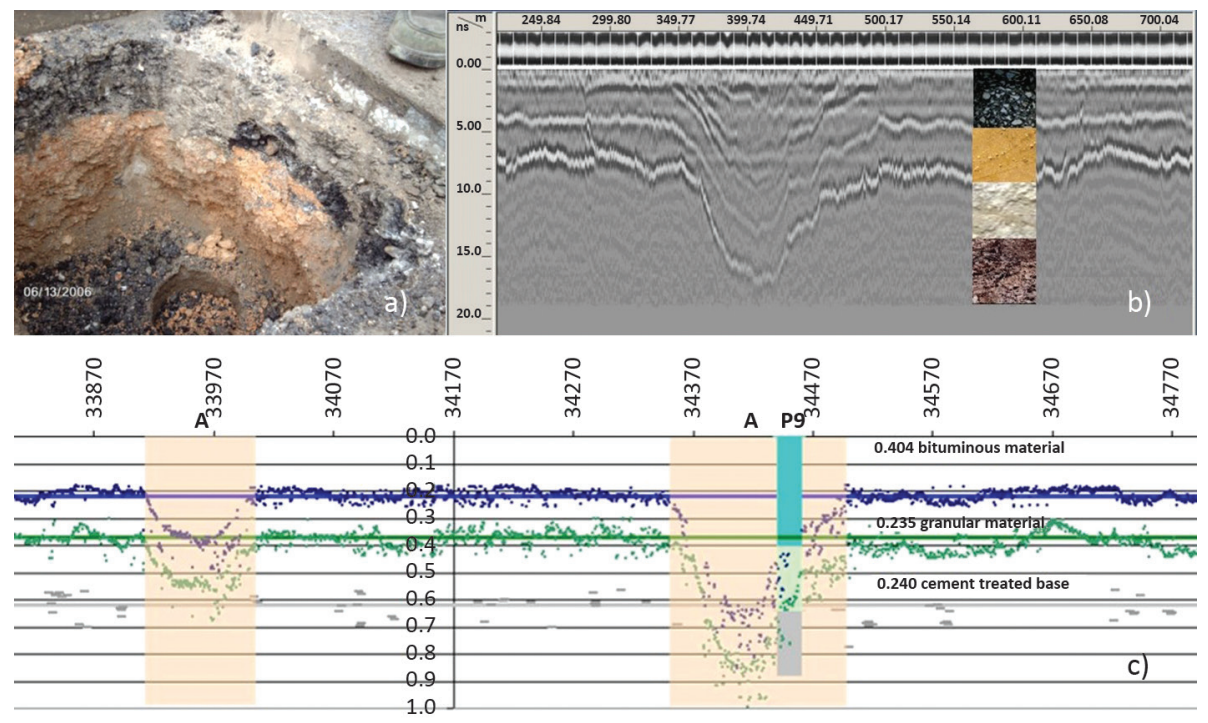

Figure I.Subgrade settlement detected with GPR: a) test pit, b) radargram, c) estimated layer thicknesses after processing

The traditional data processing of the results is based on the signal transformation from travel time of the wave into thickness [2], [4]. This procedure is based on the 
wave speed in the medium and it generally requires core sampling and test pits to calculate the wave speed in pavement layers, i.e. in bituminous layers, granular layers, soil, etc. This sampling interferes with the traffic and requires safety measures for technical personnel. An approach that enables data processing with a significant reduction in cores is presented in the next section.

\subsection{Data collection and processing for coreless assessment of thickness}

A measuring methodology that enables data processing without core calibration is presented in this approach.The data processing is based on the Common Mid Point (CMP) procedure. The CMP is generally applied to ground coupled antennas. The application of CMP in the case of air coupled antennas that are used for pavement evaluation is more complex in terms of processing, which is due to wave propagation in air.

A methodology based on the use of two pairs of air coupled antennas was successfully developed under the framework of the TRIMM EU Project (http://trimm.fehrl.org). The principle is based on the use of one transmitting antenna and two receiving antennas, and then the CMP approach is applied to the signal.

In the case only one pair of antenna is available, a simplified approach developed at LNEC [5] is used.The tests are performed with only one pair of antennas at different distances between the transmitter and the receiver. The signal gathered in different alignments measured in this way is processed, and the wave speed propagation in bituminous layer is calculated. In this way, the thickness can be deducted using the wave speed.

A case study involving monitoring and evaluation was performed on a $4.4 \mathrm{~km}$ motorway section, with $0.125 \mathrm{~m}$ bituminous layer and $0.20 \mathrm{~m}$ unbound layer.The GPR survey was carried out, at traffic speed, using a pair of I.8 GHz antennas along the exterior wheel paths of the lanes. The GPR data was recorded using three different antenna offsets (distances between the receiver and the transmitter antennas): $0.28 \mathrm{~m}, 0.67 \mathrm{~m}$, and $0.97 \mathrm{~m}$.

The developed methodology was applied to two points, with the same design thickness and different response in deflection, when tested with the Falling Weight Deflectometer, consequently revealing different structural behaviour.The methodology applied enabled detection of distinct thicknesses between the two locations, which explained the difference in structural response. The estimated thicknesses obtained using the CMP AC method amounted to $0.186 \mathrm{~m}$ and $0.132 \mathrm{~m}$, for pk 0+000 and pk $0+200$, respectively. The estimated values were similar to the ones obtained by the surface reflection method $(0.18 \mathrm{I} \mathrm{m}$ and $0.128 \mathrm{~m})$. The testing methodology and data processing is described in this study.

To allow continuous interpretation based on the Common Mid-Point approach for each survey line, the GPR data need to be recorded using different antenna offsets, considering variable distances between the receiver and the transmitter antennas. Thus, the thickness of the bituminous layer was calculated combining the data from three different GPR offsets $(A=0.28 \mathrm{~m}, B=0.67 \mathrm{~m}$ and $C=0.97 \mathrm{~m})$ as shown in Figure 2, based on the CMP-AC [6]. 


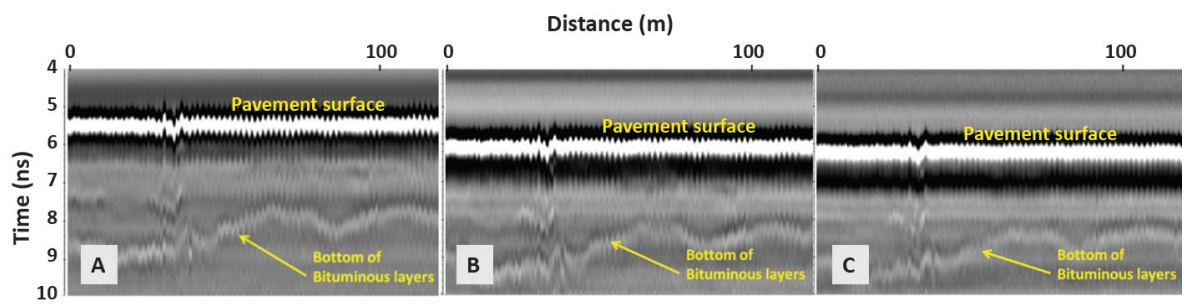

Figure 2. GPR measurements for three offsets:A) $0.28 \mathrm{~m}$, B) $0.67 \mathrm{~m}, \mathrm{C}) 0.97 \mathrm{~m}$

For each sample, the A-Scans from different antenna offset configurations were merged and the correction of the signal start time was performed adapting the surface reflection wave to the velocity of the electromagnetic wave in the air, $0.3 \mathrm{~m} /$ ns (Figure 3).

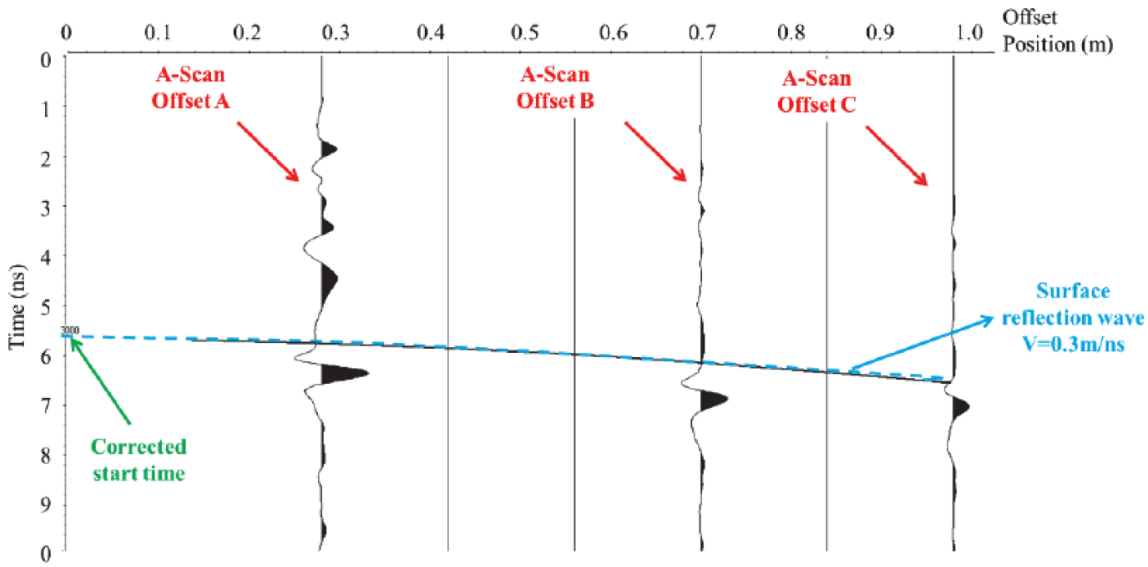

Figure 3. CMP signal start-time correction [5]

The velocity of wave propagation in the bituminous layer (first layer) was determined using the CMP-velocity analysis from ReflexW applied to the merged corrected GPR data (Figure 3). The procedure consisted in the adjustment of reflection by varying the boundary and the velocity of the hyperbolas of the CMP-velocity analysis manual adaptation (Figure 4).

Based on the known velocity of wave propagation in the bituminous layer (v), the dielectric value of the material $(\varepsilon)$ was calculated using Eq. (I). Table I shows the velocity results, dielectric value and thickness for the bituminous layer, obtained from the CMP-AC, at the case study points (pk 0+000 and pk 0+200).

$\mathrm{v} \cong \mathrm{c} / \sqrt{ } \varepsilon ; \mathrm{c}=0.3 \mathrm{~m} / \mathrm{ns}$ (speed of light in vacuum) 


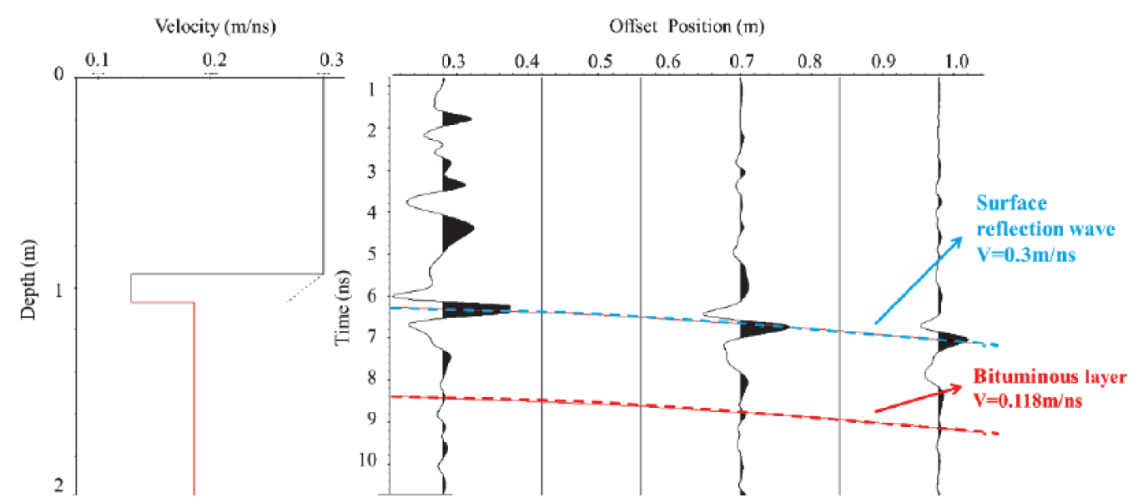

Figure 4. Example of CMP velocity analysis [5]

Table I.Wave velocity, dielectric value and thickness obtained using CMP-AC

\begin{tabular}{|c|c|c|c|c|c|}
\hline Location & $\begin{array}{c}\text { Hdesign } \\
{[\mathrm{m}]}\end{array}$ & $\begin{array}{c}\mathbf{t} \\
{[\mathrm{ns}]}\end{array}$ & $\begin{array}{c}\text { Velocity } \\
{[\mathrm{m} / \mathrm{ns}]}\end{array}$ & $\varepsilon$ & $\begin{array}{c}\text { hCMP-AC } \\
{[\mathrm{m}]}\end{array}$ \\
\hline $0+000$ & 0.125 & 3.154 & 0.118 & 6.5 & 0.186 \\
\hline $0+200$ & 0.125 & 2.041 & 0.129 & 5.4 & 0.132 \\
\hline
\end{tabular}

The methodology applied has proven to be a potential tool for layer thickness estimation, although automation in the data processing is required to make it time efficient.

\subsection{Signal processing in frequency domain}

A GPR expedite parameters definition based on signal processing in frequency domain has recently been studied in order to improve the information obtained from the GPR signal.The signal processing in frequency domain is a potential tool for detecting changes in the characteristics of the material tested, which is not limited to thickness only. It was applied at research level for detecting damage in airport pavements, using ground coupled antennas [7].

The application of this approach to the assessment of railway infrastructure is presented in this study as an example of possible infrastructure monitoring at the network level [8].The measurements were performed with a $400 \mathrm{GHz}$ air coupled antenna.

In this methodology, four new parameters are calculated, two in time domain and two in frequency domain. They aim to analyse GPR data, obtained in railway tracks, in a more user-friendly way for "non-GPR professionals" and to identify locations in the track where changes in the infrastructure occur. The parameters used in this approach are:

- in time domain, $z$ and $d z$;

- in frequency domain, $Z$ and $d Z$ 
which are defined by equations Eq. (2) to Eq. (5):

$z=\int_{t_{1}}^{t_{2}}|a| d t$

$d z=\int_{t_{1}}^{t_{2}}\left|a_{S}-a_{L, m}\right| d t$

$Z=\int_{f_{1}}^{f_{2}}|A| d f$
$d Z=\int_{f_{1}}^{f_{2}}\left|A_{S}-A_{L, m}\right| d f$

where: a and A are the GPR signal amplitudes in the time and frequency domains, respectively; subscripts $S$ and $L$ denote the short and long sliding windows and $m$ denotes the averaged signal in the specified window; $t_{1}$ and $t_{2}$ are the lower $(7 \mathrm{~ns})$ and upper ( $16 \mathrm{~ns}$ ) values of the time interval of the signal under analysis; $f_{1}$ and $f_{2}$ are the lower $(0.7 \mathrm{GHz})$ and upper $(2.0 \mathrm{GHz})$ values of the frequency range of the signal under analysis. Therefore, $\mathrm{z}$ and $\mathrm{Z}$ correspond to the areas under $|\mathrm{a}|$ and $|\mathrm{A}|$ plots, respectively, in the selected time and frequency ranges, while $\mathrm{dz}$ and $\mathrm{dZ}$ correspond to the differences in area of the GPR signal amplitude between the short and long sliding windows, respectively, in the selected time and frequency ranges.

Examples of the original signal amplitude in the time (a) and frequency (b) domains are presented in Figure 5 in terms of the mean or averaged signal (denoted by subscript $\mathrm{m})$ over the shorter $\left(\mathrm{a}_{\mathrm{S}, \mathrm{m}}\right.$ and $\left.\mathrm{A}_{\mathrm{S}, \mathrm{m}}\right)$ or longer $\left(\mathrm{a}_{\mathrm{L}, \mathrm{m}}\right.$ and $\left(\mathrm{a}_{\mathrm{L}, \mathrm{m}}\right)$ sliding windows; percentiles $5 \%$ and $95 \%$ of the longer window are also plotted to illustrate the variability of the signal [8].

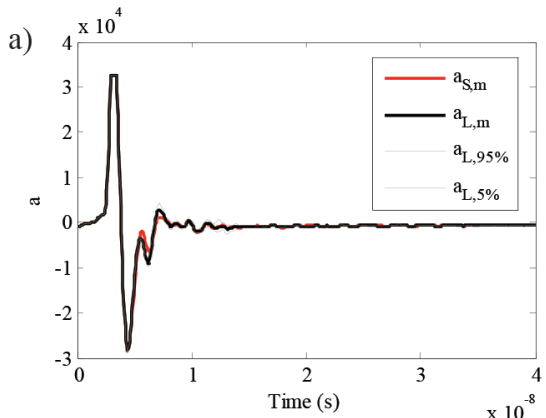

b)

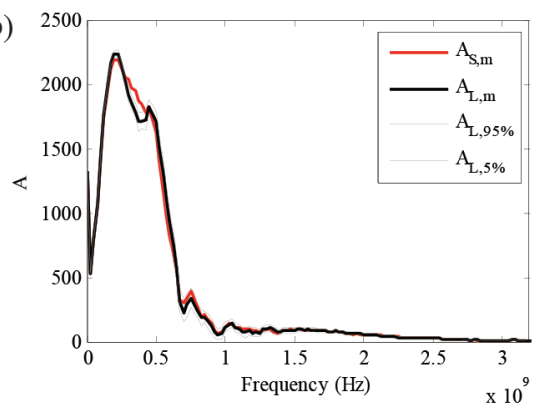

Figure 5. Amplitude of the GPR signal: a) in time domain, b) in frequency domain 
Examples of application of the proposed methodology to a track section of an existing line are presented in this section. The GPR data used to illustrate the application of the approach were acquired with the $400 \mathrm{MHz}$ antenna, during the testing campaigns performed twice per year in the national railway network by the Portuguese Railway Administration. In addition, the track geometry data recorded during the abovementioned campaigns were available for the track condition analysis.

Various data can be obtained based on this approach, which depends on the type of testing campaign and on the parameters analysed. Three examples are presented: first, a comparison between campaigns performed at the same time of the year in consecutive years, second, a comparison between campaigns performed in different seasons (winter vs summer) of the same year and, finally, a combination of track geometry results, namely the longitudinal levelling, and a GPR parameter in frequency domain is presented. In the first application, it is possible to detect changes in GPR response in different years. Figure 6 depicts an example of $Z$ values, considering sliding window lengths of $L=200 \mathrm{~m}$ and $S=10 \mathrm{~m}$, calculated for a $10 \mathrm{~km}$ stretch of an in-service railway line, obtained from GPR signals acquired in the summers of 2015 , 2016, and 2017 (in black, blue, and red, respectively) and considering $t_{1}=7 n s, t_{2}=16$ $n s, f_{1}=0.7 \mathrm{GHz}$, and $f_{2}=2.0 \mathrm{GHz}$. It can be observed, for example between $\mathrm{km} 2.5$ and $\mathrm{km} \mathrm{3.3,} \mathrm{that} \mathrm{the} Z$ value decreased between 2016 and 2017. This can be explained by a maintenance action (ballast renewal) that was undertaken in this period, which changed the wave response in frequency domain.
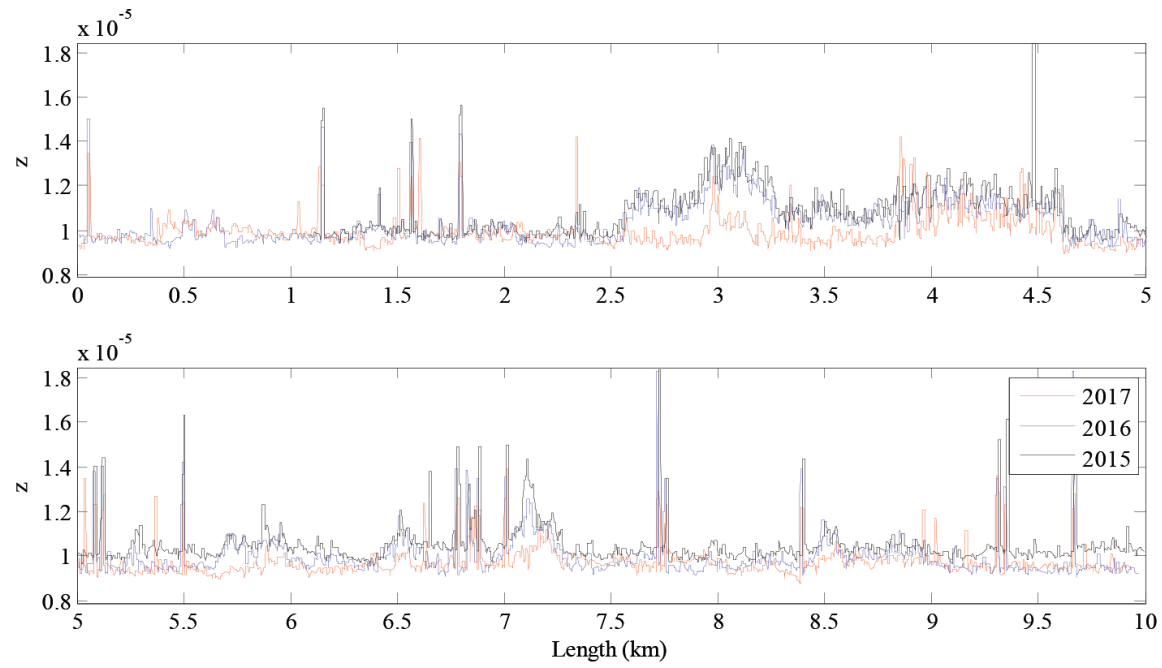

Figure 6. GPR parameter $z$, in frequency domain, for data from the summers of $20 I 5,2016$ and 2017.

The comparison between summer and winter campaigns when analysing the $d Z$ parameter in the frequency domain, as presented in Figure 7, enables detection of zones with different water content. The difference between summer and winter 
is quite visible in the diagram, mainly from $\mathrm{km} 2.5$ to $\mathrm{km} \mathrm{3.3.} \mathrm{This} \mathrm{can} \mathrm{be} \mathrm{related}$ to the highly fouled ballast, which retains water due to presence of fine particles between ballast stones, on the same section that was re-ballasted in 2017 (Figure 6). Finally, when combining the GPR $d Z$ parameter in the frequency domain with the track longitudinal levelling measurement, changes in $\mathrm{dZ}$ can be identified in the same locations where the longitudinal levelling is poorer, as can be observed in Figure 8.
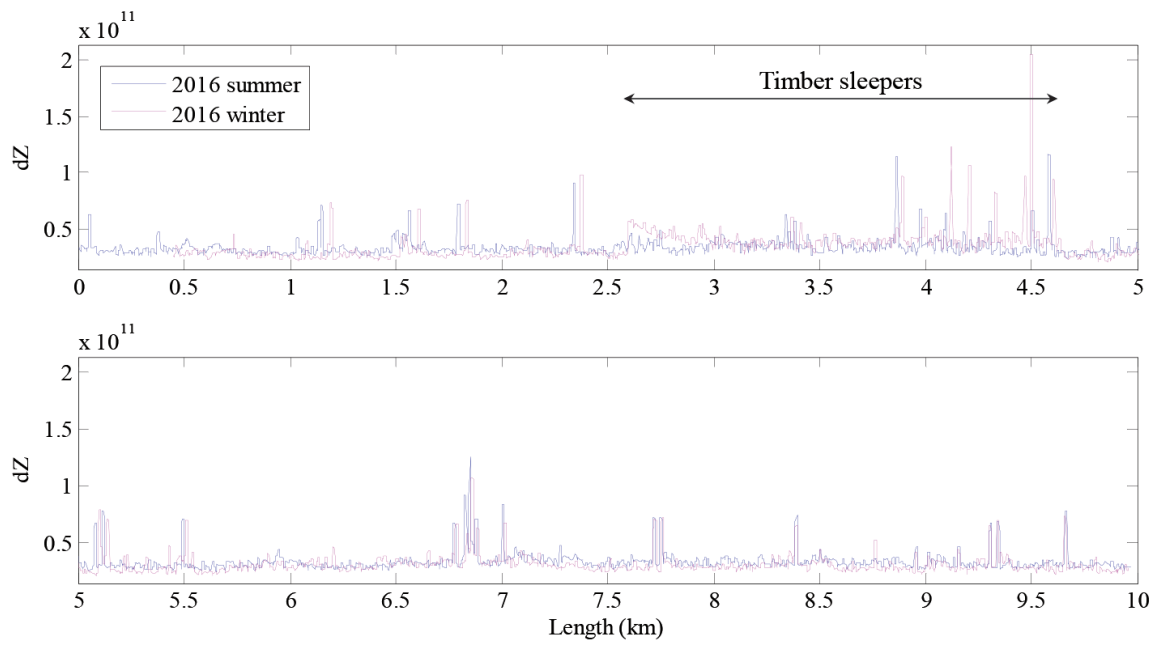

Figure 7. GPR parameter $d Z$, in the frequency domain, measured in January (winter) and July (summer) of 2016
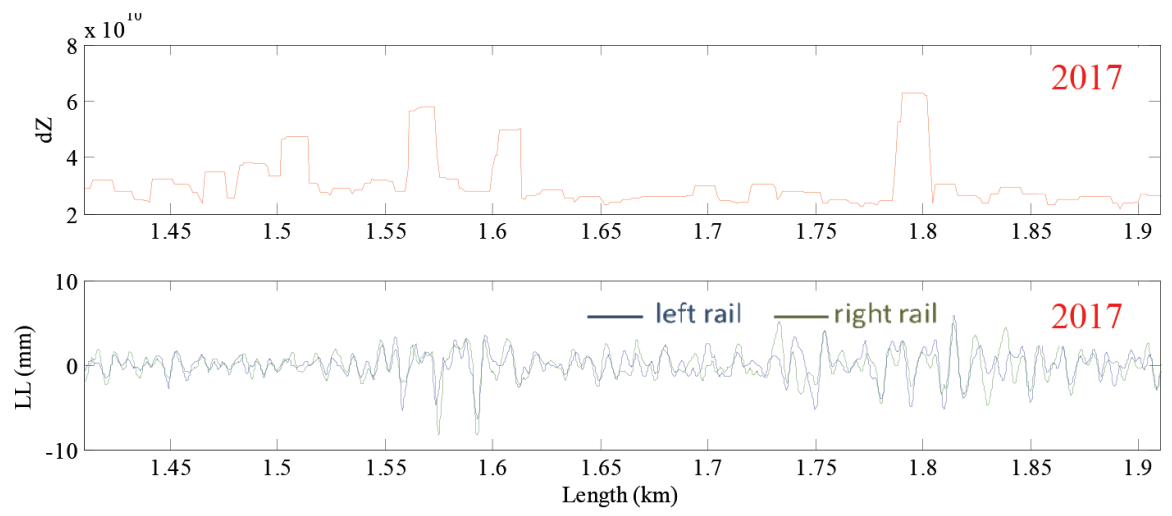

Figure 8. GPR parameter $\mathrm{dZ}$ and the Longitudinal Level (LL) of the left (blue) and right (green) rails, from the survey conducted in the summer of 2017. 
Even though it is for now mainly applied at the research level, for signal frequency analysis, the GPR use seems promising at the network level as a tool for detecting changes in the structure over time, and for identification of defects, which includes track geometry monitoring parameters.

\section{Building Information Modelling tool for pavement management}

Building Information Modelling (BIM) is a methodology that allows representation of the structural and functional characteristics of a construction, including activities and other information. BIM intends to give an impulse in order to standardize information and facilitate communication, effectively sharing and integrating the participants in the constructive process. Thus, the main feature of BIM is a three-dimensional modelling system that includes the management, sharing and exchanging data across the entire life cycle of a structure, where each element or object has information of its physical data.

The BIM methodology allows for better coordination, enabling simultaneous and realtime access, a quick detection of conflicts between components and, consequently, a cost reduction.

This work is based on the main aspects of road pavement evaluation campaigns, implemented in a case study of a pavement in service [9]. This was conceived in a BIM environment where the potential of this tool is presented with regard to pavement condition monitoring, in which the data resulting from these evaluation campaigns are monitored, with a view, in a more intuitive way, to understand the evolution of the components of this pavement.

It is also intended to evaluate the practical applicability of the BIM concept implemented in the case study, which seeks to emphasize the definition of elements and the representation of information through more expeditious methodologies and greater organizational nature. That results in an optimization of the infrastructure, increasing the levels of safety, quality, and cost.

In this sense, it is more important to a priori understand the methodologies of inspection and monitoring of existing infrastructures, and to understand how the data can be framed so as to establish a model for recording relevant structure-related information in a database structured by objects.

Three applications of BIM are presented as examples. The first one is the use of BIM in the study of a $1.6 \mathrm{~km}$ long test section [9], constructed to validate a structural solution for rehabilitation of a pavement. Various rehabilitation stages were modelled, 


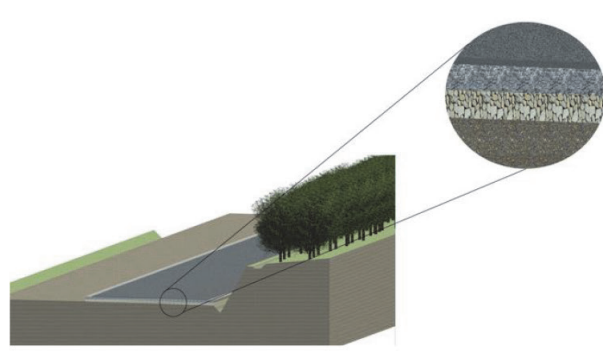

Existing structure

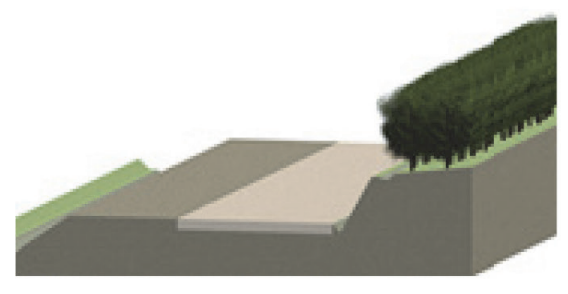

Subgrade reinforcement layer

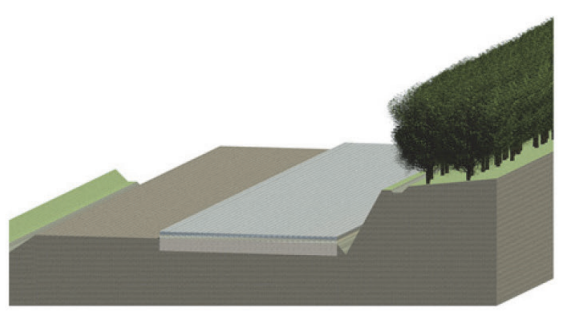

Base layer construction

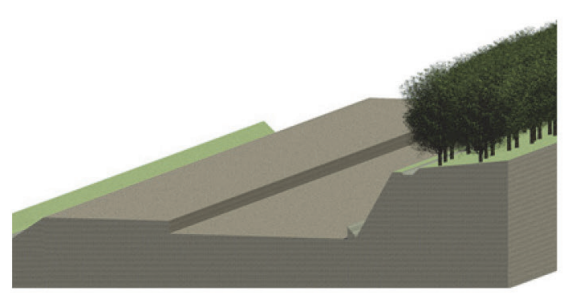

Removal of pavement layers

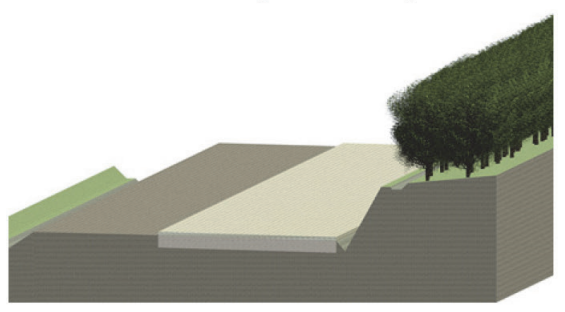

Sub-base layer construction

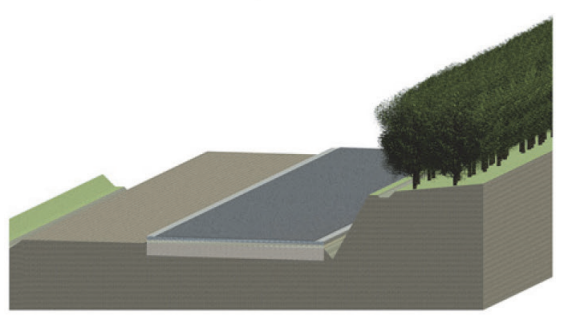

New pavement structure

Figure 9. Modelling various phases of test section rehabilitation [9]

This process also enabled calculation of the quantity of each material removed and overlaid and also, when available, calculation of the cost of these materials.

Another application is aimed at modelling structural characteristics of the pavement measured through load tests with a Falling Weight Deflectometer [2], [10]. Two parameters were modelled; the central deflection DI (Figure 10) that reflects general structural condition of the pavement, and the farther deflection D7, located at 1.8 $\mathrm{m}$ from the centre of the load plate, which reflects the stiffness of the subgrade. Figure II shows the DI scale modelled in BIM. 


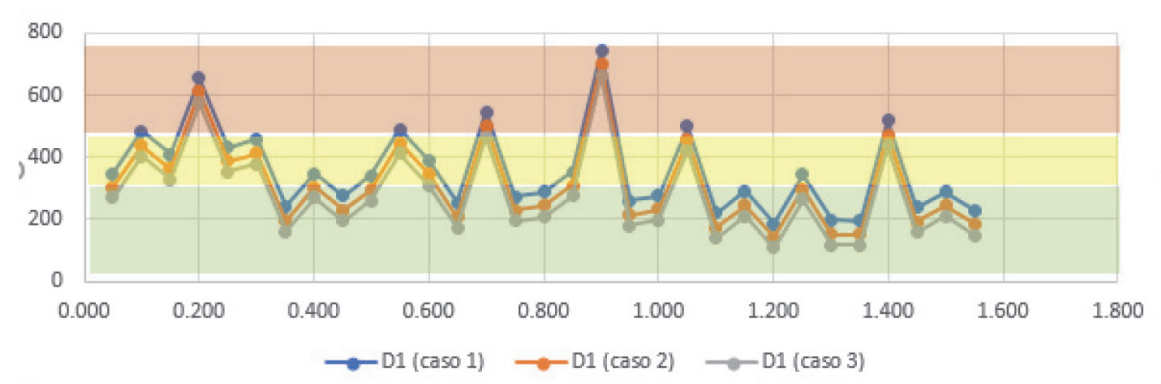

Figure I0.DI measured with FWD on the test section and the colour legend adopted

$$
\mathrm{D} 1(\mu \mathrm{m}) \quad \begin{aligned}
& \square 300-500 \\
& \square<300 \\
& \square>500
\end{aligned}
$$

Figure I I. BIM modelling of DI along the test section

Finally, BIM was applied to represent results of visual inspection of an urban pavement (Figure 12).
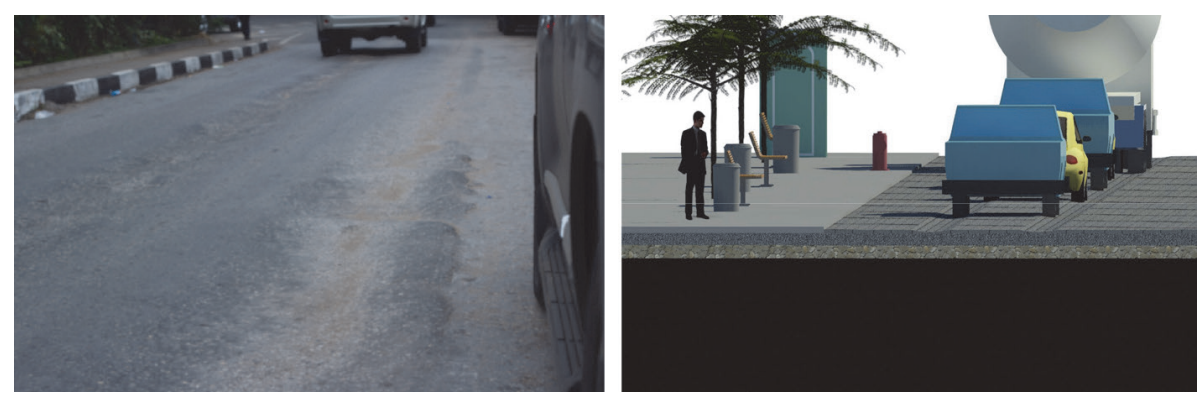

Figure I 2. BIM modelling of rutting

If updated regularly, modelling structural characteristics of pavement in BIM provides a visual indicator of pavement condition evolution in time, allowing for a better management and maintenance planning. 


\section{Remote sensing}

Another trend in pavement monitoring is the use of satellites for remote monitoring of settlements and movements.

As an example, Figure 13 presents a graph of the settlement on a road section (the red dot) near Lisbon, followed in the framework of the INFRASAR project developed at LNEC for studying application of RADAR interferometry as a means to determine displacement in buildings and transport infrastructure facilities [I I].

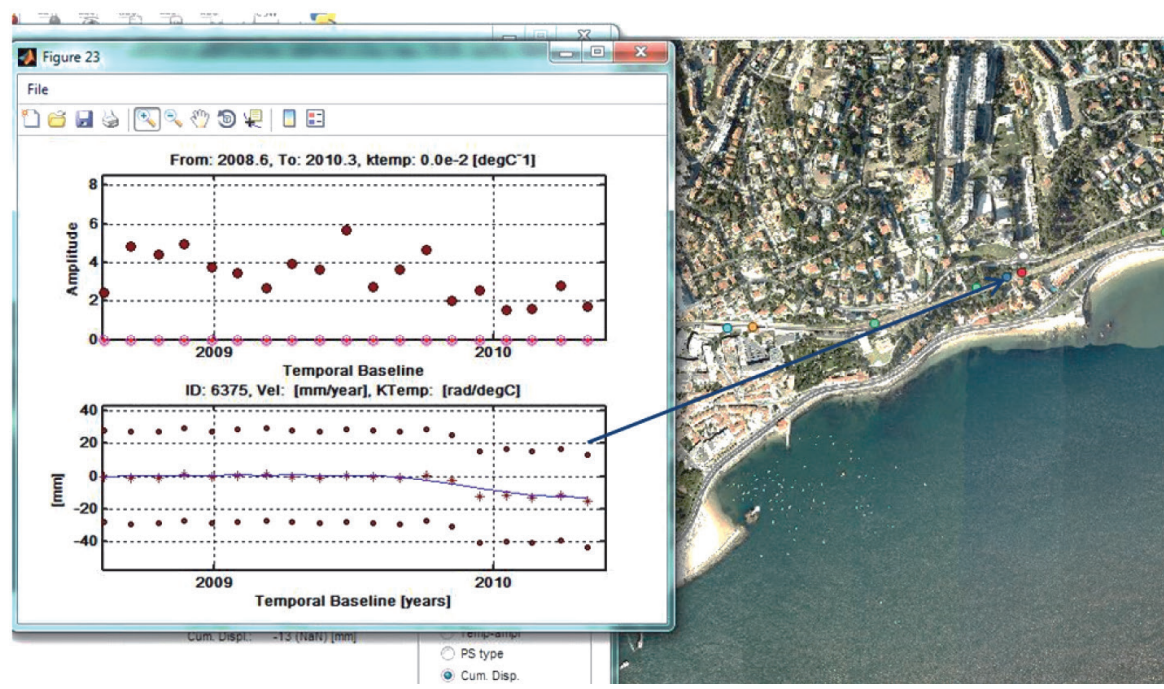

Figure I3. Road settlement detected with RADAR interferometry [I I]

\section{Conclusion}

Pavement monitoring is an important tool for maintenance management. Currently available non-destructive tests provide crucial information on pavement condition. Among these tests, the Ground Penetrating Radar has recently been increasingly used in Europe for pavement evaluation.

This paper presents two main features for better use of GPR through a different testing methodology and signal frequency processing.

The development of building information modelling (BIM) as a tool that can integrate evaluation results in an updated pavement model is also addressed. The BIM model, integrating automatically the tests results can reflect the evolution of pavement condition along life cycle and can represent a basis for performance indexes development and validation.

Another trend is the use of remote sensing to monitor pavement settlement, which is considered as quite useful because, in addition to its precision, the data are provided free. 
The importance of the testing technology and modelling is highlighted as a tool for managing pavements in an economically efficient way that guarantees proper behaviour and an extended life cycle of pavements.

\section{References}

[I] Saarenketo, T.: Electrical properties of road materials and subgrade soils and the use of Ground Penetrating Radar in traffic infrastructure Surveys. PhD. Thesis, University of Oulu, Oulu, SuomiFinland. 2006.

[2] Fontul, S.: Structural evaluation of flexible pavements using non-destructive tests. PhD Thesis, University of Coimbra, Coimbra, Portugal, 2004

[3] Loizos,A., \& Plati, C. "Accuracy of pavement thicknesses estimation using different ground penetrating radar analysis approaches”. NDT \& E International, 40(2), I47-157. 2007.

[4] Domitrović,.., Bezina, S., Rukavina, T.,Stančerić, I.: Investigating the use of GPR for pavement condition assessment. Fifth International Conference on Road and Rail Infrastructure. Zadar, Croatia, 2018 DOI: $10.5592 / C O / C E T R A .2018 .873$

[5] Marecos, V.: Optimisation of Ground Penetrating Radar testing at traffic speed for structural monitoring of pavements. Ph.D.Thesis, Vigo University,Vigo, Spain, 2018.

[6] Marecos, V., Fontul, S., Solla, M., Antunes, M.L.: Evaluation of the feasibility of Common Mid-Point approach for air-coupled GPR applied to road pavement assessment. Measurements 2018, 128, 295305, 2018, doi: 10.1016/j.measurement.2018.06.062

[7] Pedret Rodés, J., Pérez-Gracia, V., Martínez-Reguero, A.: Evaluation of the GPR frequency spectra in asphalt pavement assessment. Construction and Building Materials 2015, 96, I8I-I88, 2015, doi: 10.1016/j.conbuildmat.2015.08.017

[8] Fontul, S., Paixão,A., Solla, M., Pajewski, L.: Railway Track Condition Assessment at Network Level by Frequency Domain Analysis of GPR Data. Remote Sens. 2018, 10(4), 559, doi: 10.3390/rs 10040559

[9] Manico, H.:Flexible road pavements in Angola. Characterization and application of BIM methodologies. MsC dissertation. Nova University of Lisbon, 2018.

[10] Domitrović, J., Rukavina, T.: Application of GPR and FWD in Assessing Pavement Bearing Capacity. Rom. J.Transp. Infrastruct. 2 II-2I (20I3). doi:I0.15I5/rjti-20I5-00I5

[II] Fonseca, A., Roque, D.: INFRASAR - SAR interferometry with permanent scatterers applied to the detection of displacements in geodynamics and infrastructures. Progress report 2014-2017 of the P2I/LNEC project, Report 166, 2018. 